\title{
Enrofloxacin Enhances the Formation of Neutrophil Extracellular Traps in Bovine Granulocytes
}

\author{
Natalja Jerjomiceva ${ }^{a}$ Hisham Seria, ${ }^{a}$ Lena Völlger ${ }^{a} \quad Y^{a n m i n g ~ W a n g ~}{ }^{c}$ \\ Nathalie Zeitouni $^{a}$ Hassan Y. Naim ${ }^{a}$ Maren von Köckritz-Blickwede ${ }^{a}$ \\ ${ }^{a}$ Department of Physiological Chemistry, University of Veterinary Medicine Hannover, Hannover, Germany; ${ }^{b}$ Department of \\ Clinical Studies, College of Veterinary Medicine, Sudan University of Science and Technology, Khartoum, North Sudan; \\ 'Department of Biochemistry and Molecular Biology, Penn State University, University Park, Penn, Pa., USA
}

\section{Key Words}

Bovine granulocytes · Neutrophil extracellular traps ·

Enrofloxacin · Cytoskeleton

\begin{abstract}
Several antibiotics are known for their ability to accumulate in neutrophils and thereby modulate the antimicrobial functions of those cells. This study demonstrates for the first time that an antibiotic, namely the fluoroquinolone enrofloxacin, enhances the formation of bovine neutrophil extracellular traps (NETs). Pharmacologically inactivated NADPH oxidase or peptidyl-arginine deiminase-4 distinctly reduced enrofloxacin-induced NET formation. Additionally, when cells were treated with cytochalasin D or nocodazole, the enrofloxacinmediated NET induction was abolished, indicating that besides oxidative burst and histone citrullination also actin and microtubule polymerization are involved in this process.
\end{abstract}

(C) 2014 S. Karger AG, Basel

\section{Introduction}

Intramammary infections as a major cause of mastitis in dairy cows have recently received a lot of attention because of their major economic impact [1]. The fluo- roquinolone enrofloxacin is authorized for use in the lactation of cattle and is one of the few antimicrobial drugs that have been recommended for the treatment of Staphylococcus aureus- and Escherichia coli-induced mastitis due to its favorable pharmacokinetic and pharmacodynamic properties. Like other fluoroquinolones, enrofloxacin exhibits a broad spectrum of antibacterial activity against both Gram-positive and Gram-negative bacteria in diseased animals [2]. The bactericidal activity of enrofloxacin is concentration dependent and is caused by the inhibition of bacterial DNA gyrase (a type-II topoisomerase), thereby preventing DNA supercoiling and DNA synthesis. Interestingly, enrofloxacin has been shown to stimulate the oxidative burst of bovine granulocytes in vitro at a concentration of $10 \mu \mathrm{g} /$ $\mathrm{ml}$ [3], which reflects a physiologically relevant concentration received in infected tissue upon treatment with enrofloxacin [4]. However, it is completely unclear whether enrofloxacin modulates additional antimicrobial granulocyte functions.

Granulocytes play a key role in the early innate immune defense against bacterial infections during mastitis in dairy cows [5]. Until a few years ago, granulocytes such as neutrophils had been thought to employ essentially 2 major antimicrobial strategies to entrap and kill invading pathogens: oxidative burst-dependent phago-

\section{KARGER}

E-Mail karger@karger.com

www.karger.com/jin (c) 2014 S. Karger AG, Basel

1662-811X/14/0065-0706\$39.50/0
Dr. Maren von Köckritz-Blickwede

Department of Physiological Chemistry

University of Veterinary Medicine Hannover

Bünteweg 17, DE-30559 Hannover (Germany)

E-Mail mkoeckbl@tiho-hannover.de 
cytosis which involves the engulfment and subsequent elimination of microbes in specialized phagolysosome compartments, and oxidative burst-independent degranulation which releases antimicrobial molecules into the extracellular milieu [reviewed by von Köckritz-Blickwede and Nizet in 6]. Recently, a third strategy was discovered, namely the formation of neutrophil extracellular traps (NETs) [7]. NETs consist of nuclear and mitochondrial DNA with associated histones and have recently been identified as a novel extracellular host innate immune defense mechanism of granulocytes that acts by mediating the extracellular entrapment and subsequent immobilization of invading pathogens [reviewed by von Köckritz-Blickwede and Nizet in 6]. Several studies have also confirmed the formation of NETs by bovine neutrophils [8-10].

The goal of this study was to investigate the effect of enrofloxacin on bovine granulocyte functions with a special focus on NET formation and to characterize the underlying biochemical mechanisms of the observed phenotypes.

\section{Methods}

\section{Drugs}

Enrofloxacin (Bayer Animal Health $\mathrm{GmbH}$ ) was dissolved in $0.1 \mathrm{M}$ sodium hydroxide $(\mathrm{NaOH})$ at a concentration of $10 \mathrm{mg} / \mathrm{ml} /$ stock. For all experiments, a final concentration of $10 \mu \mathrm{g} / \mathrm{ml} \mathrm{enro-}$ floxacin was used. A respective concentration of $\mathrm{NaOH}$ was used as the vehicle control in all experiments and is described as the control (Ctr) throughout this paper.

\section{Isolation and Preparation of Bovine Granulocytes}

Bovine granulocytes were isolated from fresh blood of healthy animals via density gradient centrifugation. Twenty milliliters of blood were layered on top of $15 \mathrm{ml}$ Biocoll (Biochrom) and centrifuged at $1,100 \mathrm{~g}$ for $30 \mathrm{~min}$ at $10^{\circ} \mathrm{C}$ (without brake). The supernatant including mononuclear cells and plasma was discarded. The resulting cell pellet including erythrocytes and granulocytes was harvested. Cells were washed with $\mathrm{H}_{2} \mathrm{O}$ to lyse erytrocytes and resuspended in RPMI containing $2 \%$ nuclease-free (heat-inactivated at $70^{\circ} \mathrm{C}$ ) fetal calf serum. Granulocyte viability was checked with a Trypan Blue dye exclusion test using a hemocytometer, and the cell suspension was adjusted to $2 \times 10^{6} \mathrm{cells} / \mathrm{ml}$ in RPMI + 2\% nuclease-free fetal calf serum (heat inactivated at $\left.70^{\circ} \mathrm{C}\right)$. Granulocytes were treated with enrofloxacin $(10 \mu \mathrm{g} / \mathrm{ml})$ or the respective vehicle control $(\mathrm{NaOH})$ for $2 \mathrm{~h}$ at $37^{\circ} \mathrm{C}$ in $5 \%$ $\mathrm{CO}_{2}$.

\section{Determination of the Phagocytic Bacterial Uptake}

Bovine granulocytes $\left(2 \times 10^{6}\right.$ cells $\left./ \mathrm{ml}\right)$ were treated with enrofloxacin for $2 \mathrm{~h}$ or cytochalasin $\mathrm{D}(10 \mu \mathrm{g} / \mathrm{ml}$ to block phagocytosis as a negative control) at $37^{\circ} \mathrm{C}$ in $5 \% \mathrm{CO}_{2}$. Then $10 \mu \mathrm{l}$ heatkilled fluorescein isothiocyanate (FITC)-labeled E. coli (K-12 strain; Sigma) or $5 \mu \mathrm{l}$ S. aureus (Wood strain; Sigma) were incubated with granulocytes for $30 \mathrm{~min}$ at $37^{\circ} \mathrm{C}$ in $5 \% \mathrm{CO}_{2}$. The cells were washed with PBS and centrifuged at $370 \mathrm{~g}$ to remove nonphagocytosed bacteria. FITC fluorescence was measured using a Beckman Coulter EPICS XL flow cytometer and recorded on a logarithmic scale from 1 to 5,000. The mean green fluorescence intensity per neutrophil (Gx-Mean of FL-1) was recorded and represents the mean relative phagocytosis of FITC-labeled E. coli or $S$. aureus per neutrophil.

\section{NET Visualization and Quantification}

Bovine $\left(1 \times 10^{6}\right.$ cells $\left./ 500 \mu \mathrm{l}\right)$ cells were seeded on poly-L-lysinecoated glass slides (centrifugation at $370 \mathrm{~g}$ for $5 \mathrm{~min}$ ) and treated with enrofloxacin for $2 \mathrm{~h}$ at $37^{\circ} \mathrm{C}$ in $5 \% \mathrm{CO}_{2}$. After incubation, cells were fixed with $4 \%$ paraformaldehyde, washed with PBS, and blocked with $2 \%$ bovine serum albumin (Sigma) in PBS $+0.2 \%$ Triton X-100 for $45 \mathrm{~min}$ at room temperature. To visualize NETs, the slides were incubated overnight at $4^{\circ} \mathrm{C}$ with mouse monoclonal anti-H2A-H2B-DNA antibodies (PL2-6, diluted 1:1,000) [11]. After incubation, the slides were washed 3 times with PBS and incubated for $45 \mathrm{~min}$ at room temperature with secondary antibody Alexa fluor 488 goat anti-mouse IgG (1:500; Invitrogen). After washing, the slides were mounted on glass slides using ProlongGold $^{\circledR}$ antifade with DAPI (Invitrogen). Washing steps were conducted with PBS and the antibodies were diluted in 2\% BSA-PBS + $0.2 \%$ Triton X-100. After mounting, the slides were analyzed by confocal fluorescence microscopy using a Leica TCS SP 5 confocal microscope with an HCX PL APO $40 \times 0.75-1.25$ oil immersion objective. Settings were adjusted with control preparations using an isotype control antibody. For each preparation, a minimum of 5 randomly selected images were acquired per slide and used for quantification of NET-producing cells. The mean value of those randomly taken images with a minimum of 100 cells per slide was used for statistical analysis. Data are expressed as percentages of NET-forming cells in relation to the total number of cells visualized with DAPI to stain all nuclei blue.

\section{Degranulation}

Bovine granulocytes $\left(2 \times 10^{6}\right.$ cells $\left./ \mathrm{ml}\right)$ were treated with enrofloxacin for $2 \mathrm{~h}$ at $37^{\circ} \mathrm{C}$ in $5 \% \mathrm{CO}_{2}$. The degranulation of granulocytes, after treatment with antibiotic compared to the vehicle control, was measured with a Beckman Coulter EPICS XL flow cytometer using the sideward scatter. Treatment of the cells with $25 \mathrm{nM}$ phorbol myristate acetate (PMA) was used as a positive control.

\section{Oxidative Burst}

Oxidative burst was determined by changes in fluorescence resulting from oxidation of the fluorescent probe $2^{\prime}-7^{\prime}$-dichlorofluorescein (DCF) in response to reactive oxygen species (ROS). Therefore, $5 \times 10^{5}$ cells $/ 250 \mu$ l were treated with enrofloxacin for $2 \mathrm{~h}$ at $37^{\circ} \mathrm{C}$ in $5 \% \mathrm{CO}_{2}$. Treatment of the cells with $25 \mathrm{nM}$ PMA was used as a positive control. After incubation, cells were further incubated with $10 \mu \mathrm{M}$ DCF for $30 \mathrm{~min}$ at $37^{\circ} \mathrm{C}$ in $5 \% \mathrm{CO}_{2}$. The cells were washed with PBS by centrifugation. The relative oxidative burst was analyzed using the fluorescence detector FL-1 of a Beckman Coulter EPICS XL flow cytometer. The mean green fluorescence intensity of all cells (x-Mean of FL-1) was recorded and represents the mean relative oxidative burst of all cells tested. 
Effect of Diphenyliodonium Salt, Nocodazole, Cytochalasin D, or YW3-56 on Enrofloxacin-Mediated NET Formation

Bovine granulocytes $\left(1 \times 10^{5}\right.$ cells $\left./ \mathrm{ml}\right)$ were treated with enrofloxacin or $\mathrm{NaOH}$ vehicle control in the presence or absence of diphenyliodonium salt (DPI, $10 \mu \mathrm{M}$; Sigma) to block the NADPH-oxidase-dependent formation of ROS, with YW3-56 $(8 \mu \mathrm{M})$ to block histone citrullination [12], with nocodazole $(10 \mu \mathrm{M}$; Sigma) to block tubulin polymerization during microtubuli formation, or with cytochalasin D (10 $\mu \mathrm{M}$; Sigma) to block the polymerization of actin filaments for $2 \mathrm{~h}$ at $37^{\circ} \mathrm{C}$ and $5 \%$ $\mathrm{CO}_{2}$. Microscopic quantification of NETs was performed as described above.

\section{Western Blot Analysis of PAD4 Expression and Histone} Citrullination

A total of $1.75 \times 10^{7}$ granulocytes, derived in equal proportions from 3 individual animals, were incubated in the presence of $10 \mu \mathrm{g} / \mathrm{ml}$ enrofloxacin or a vehicle control for $2 \mathrm{~h}$ at $37^{\circ} \mathrm{C}$ and then centrifuged for $7 \mathrm{~min}$ at $140 \mathrm{~g}$. The cell pellet was resuspended in $200 \mu \mathrm{l}$ lysis buffer with proteinase inhibitors and incubated for $2 \mathrm{~h}$ at $4^{\circ} \mathrm{C}$ under constant agitation. The samples were then centrifuged for $15 \mathrm{~min}$ at $13,000 \mathrm{~g}$ and $4^{\circ} \mathrm{C}$. Equal protein amounts from each sample (enrofloxacin-treated and vehicle control cells) were denaturated in boiling Laemmli buffer $+0.01 \%$ DTT for $5 \mathrm{~min}$. Samples were separated in 15\% SDSPAGE. After electrophoresis, proteins were transferred to PVDF membranes. The membranes were blocked for $1 \mathrm{~h}$ at room temperature in Tris-buffered saline $+0.1 \%$ Tween 20 (TBS) (supplemented with $5 \%$ fat-free dried milk and $3 \%$ bovine serum albumin) and then incubated with the primary antibodies polyclonal rabbit anti-PAD4 (1:2,000) [13], polyclonal rabbit anti-citrulline (R2 + R8 + R17) histone H3 (1 $\mu \mathrm{g} / \mathrm{ml}$; Abcam), polyclonal rabbit anti-total histone $\mathrm{H} 3(1 \mu \mathrm{g} / \mathrm{ml} ; \mathrm{Abcam})$, and monoclonal mouse anti- $\beta$-actin (1:10,000-diluted; Santa Cruz) diluted in TBS (supplemented with $2 \%$ fat-free dried milk) overnight at $4{ }^{\circ} \mathrm{C}$ under agitation. Before primary antibody incubation, membranes were cut horizontally at $55 \mathrm{kDa}$ in order to avoid nonspecific binding; the upper part of the membrane was used to detect PAD4 (74 kDa), while the lower part was used to detect $\beta$-actin $(42 \mathrm{kDa})$ and citrullinated $(17 \mathrm{kDa})$ or total histone $\mathrm{H} 3(17 \mathrm{kDa})$. After washing in TBS, the blots were incubated for $1 \mathrm{~h}$ at room temperature with the respective secondary anti-rabbit $(1: 5,000)$ for PAD4, citrullinated, and total histone $\mathrm{H} 3$ and anti-mouse $(1: 5,000)$ for $\beta$-actin antibodies diluted in TBS with $5 \%$ fat-free dried milk. The membranes were

Fig. 1. Effect of enrofloxacin (Enro) on the antimicrobial defense strategies of bovine granulocytes. Granulocytes were isolated via density gradient centrifugation and treated with $10 \mu \mathrm{g} / \mathrm{ml}$ enrofloxacin for $2 \mathrm{~h}$. a Relative degranulation measured by flow cytometry. Neutrophil phagocytosis of FITC-labeled bacteria: E. coli (b) and $S$. aureus (c). PMA (25 nM) was used as a positive control, and the phagocytosis-blocking agent cytochalasin D (Cyt D) was used as a negative control. $\mathbf{d}$ Relative oxidative burst measured by flow cytometry using DCF as a fluorescent probe. The results of a minimum of 3 independent experiments were analyzed using a paired, one-tailed t test. ${ }^{*} \mathrm{p}<0.05$. e-g Forma- washed in TBS followed by development with SuperSignal West Femto Chemiluminescent Substrate reagents (Pierce, Thermo Scientific).

\section{Antimicrobial Activity of Enrofloxacin-Treated Granulocytes} against MRSA

The S. aureus strain LAC (pulsed-field type USA300) and its respective nuclease (nuc) mutant [14] were used in this study. In a previous study, the wild-type strain was shown to degrade NETs efficiently, whereas the nuc mutant was susceptible to NET-mediated antimicrobial activity [13]. Bacteria were grown in brain heart infusion medium at $37^{\circ} \mathrm{C}$ with shaking. Fresh overnight cultures were diluted 1:100 in brain heart infusion medium and then grown to a mid-logarithmic growth phase $\left(\mathrm{OD}_{600}=0.7\right)$ for use in experiments. Granulocytes treated with enrofloxacin or a vehicle control (as described above) were infected with wild-type and nuc mutant bacteria at a multiplicity of infection of 2 bacteria per cell. The plates were centrifuged at $370 \mathrm{~g}$ for $5 \mathrm{~min}$ and incubated for $60 \mathrm{~min}$ at $37^{\circ} \mathrm{C}$ in $5 \% \mathrm{CO}_{2}$. Serial dilutions in sterile PBS were plated on THA plates for enumeration of the surviving bacteria. The data are presented as percentages of surviving bacteria in the presence of granulocytes treated with enrofloxacin compared to surviving bacteria in the presence of granulocytes treated with $\mathrm{NaOH}(100 \%)$. In control experiments, both strains showed a similar sensitivity against the antimicrobial activity of enrofloxacin alone.

\section{Statistical Analysis}

Data were analyzed using Excel 2003 (Microsoft) and GraphPad Prism 5.0 (GraphPad Software). The number of individual experiments and images used for statistical analysis is indicated in each figure legend. Differences between the two groups were analyzed using a paired (matched data points of each individual experiment) or unpaired (nonmatched data points of each individual experiment) one-tailed Student $t$ test. The significance is indicated as $* \mathrm{p}<0.05,{ }^{* *} \mathrm{p}<0.005$, and ${ }^{* * *} \mathrm{p}<0.001$.

\section{Results and Discussion}

\section{Effect of Enrofloxacin on the Antimicrobial Defense Strategies of Bovine Granulocytes}

Primary blood-derived granulocytes were isolated from fresh blood of healthy cows via density gradient tion of NETs after treatment of granulocytes with enrofloxacin or the vehicle control $\mathrm{NaOH}$ (Ctr) in the presence or absence of DPI to block the NADPH-oxidase-dependent formation of ROS. NETs were visualized by immunofluorescence microscopy using an antibody against histone-DNA complexes (green) and DAPI to stain DNA (blue) (colors refer to the online version only). e, f Representative images of the quantification depicted in $\mathbf{g}$. The results of 3 independent experiments with 5 images each were analyzed using a paired, one-tailed t test $(* \mathrm{p}<0.05)$. n.s. $=$ Not significant.

(For figure see next page.) 


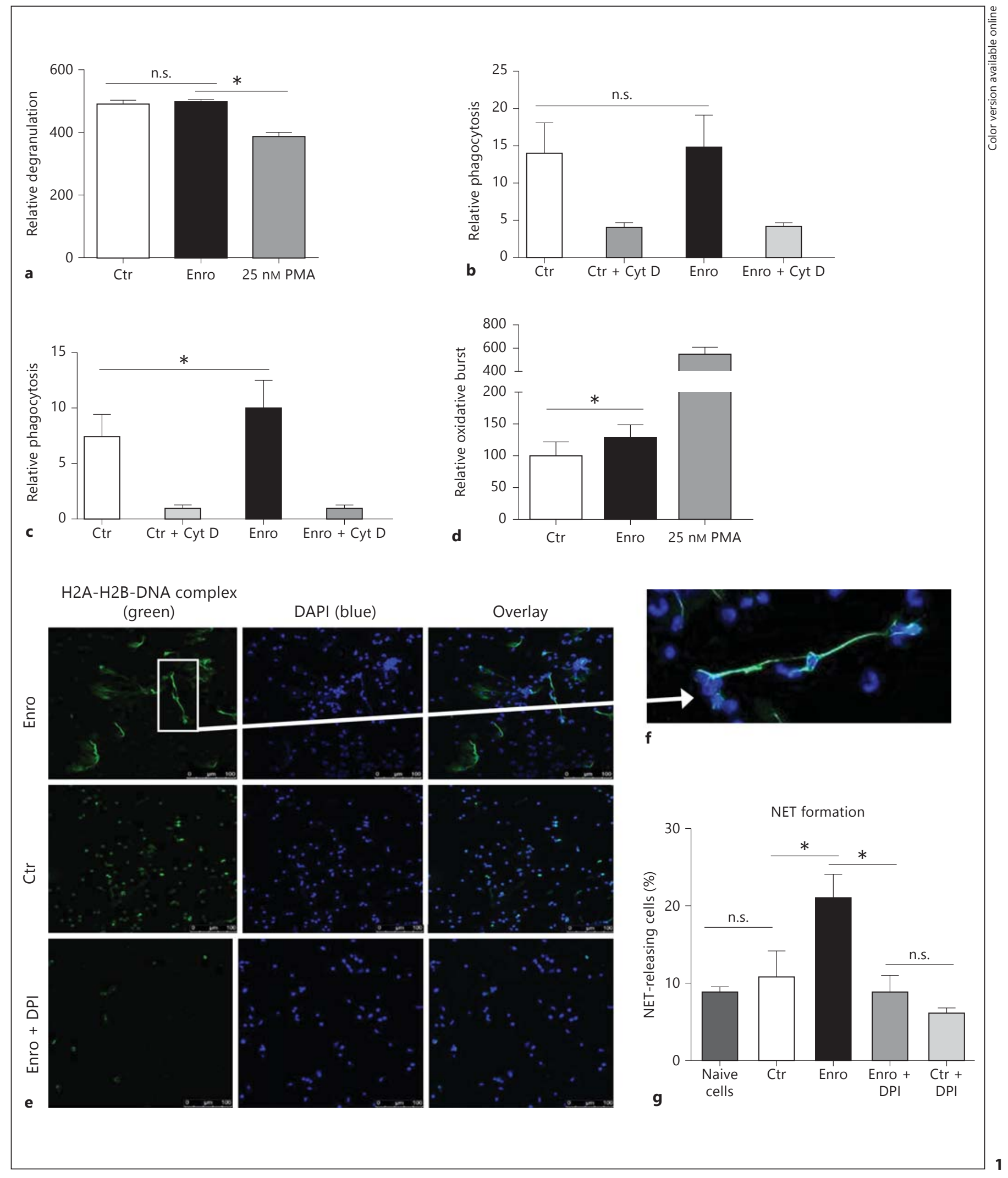

Enrofloxacin Induces Bovine NETs 
centrifugation. After treatment of the cells with $10 \mu \mathrm{g} /$ $\mathrm{ml}$ enrofloxacin or a vehicle control, phagocytosis, degranulation, oxidative burst, and NET formation were analyzed. Quantitative measurement of neutrophil degranulation after treatment with enrofloxacin was performed using flow cytometry based on quantification of cell granularity using the sideward scatter. The results in fig. la show that enrofloxacin had no effect on the granularity of the cells. PMA was used as a positive control and showed significant degranulation of the treated cells.

In a next step, granulocytes were incubated in the presence of fluorescence-labeled E. coli or S. aureus bioparticles. In accordance with a previous publication by Hoeben et al. [3], enrofloxacin treatment of the cells did not alter the phagocytosis of E. coli bioparticles (fig. 1b). However, a significant uptake of $S$. aureus bioparticles was detectable after treatment with enrofloxacin compared to the vehicle control (fig. 1c). These data indicate that enrofloxacin modulates the oxidative burst-dependent defense strategies of granulocytes, e.g. the phagocytosis of $S$. aureus. Thus, to confirm that enrofloxacin alters the oxidative burst, flow cytometry studies were performed using the cell-permeant fluorogenic probe DCF. Again, PMA was used as positive control to exclude technical problems. As shown in fig. 1d, enrofloxacin significantly induced the production of ROS. This finding is in line with the publication of Hoeben et al. [3] in which an increased chemiluminescense of bovine granulocytes was demonstrated [3].

Finally, the formation of NETs was quantified using immunofluorescent microscopy with histone ( $\mathrm{H} 1$ and $\mathrm{H} 2$ )-DNA-specific antibodies. Interestingly, we demonstrated that enrofloxacin significantly induces the formation of NETs in bovine granulocytes after $2 \mathrm{~h}$ of treatment with enrofloxacin compared to cells treated with $\mathrm{NaOH}$ as a vehicle control (Ctr) (fig. 1e, g) or naive cells (fig. 1g). To see if blocking of the oxidative burst alters enrofloxacin-dependent NET induction, bovine granulocytes were incubated with DPI to block the NADPH-dependent formation of ROS. As shown in fig. 1g, blocking of the oxidative burst significantly decreased the enrofloxacin-induced NET formation, indicating that the phenomenon is ROS dependent.

\section{Biochemical Mechanisms Associated with the \\ Enrofloxacin-Induced Formation of NETs}

The histone hypercitrullination catalyzed by peptidylarginine deiminase 4 (PAD4) has been shown to mediate one of the first steps involved in chromatin decon- densation by hypercitrullination of histones such as $\mathrm{H} 3$ during the formation of NETs $[15,16]$. Interestingly, we observed that enrofloxacin distinctly induced the relative PAD4 protein expression in bovine granulocytes (fig. 2a). Thus, in control experiments PAD4 activity was confirmed by analyzing histone $\mathrm{H} 3$ citrullination and it was revealed that enrofloxacin treatment of the cells leads to an increased presence of citrullinated $\mathrm{H} 3$ relative to the total $\mathrm{H} 3$ expression (fig. 2b). Furthermore, blockage of PAD4-mediated histone citrullination using a well-characterized PAD4 inhibitor, namely YW3-56 [12], revealed a partial decrease in enrofloxacin-mediated NET formation (fig. 2c). These data suggest that PAD4-mediated histone citrullination has only a minor effect on enrofloxacin-mediated NET formation in bovine granulocytes.

Previous studies have shown that overlapping mechanisms are involved in LPS-induced NET formation in human neutrophils [15]. Importantly, the authors identified that, besides PAD4-mediated histone citrullination, also functional tubulin and actin filaments are required. To additionally test the involvement of microtubules and actin filaments in enrofloxacin-mediated NET formation, we incubated granulocytes with nocodazole, a drug that interferes with tubulin polymerization into microtubules, or cytochalasin $\mathrm{D}$, a drug that disrupts the polymerization of actin filaments. Both treatments significantly decreased the NET production in bovine granulocytes after $2 \mathrm{~h}$ of incubation (fig. 2d, e). Thus, our data indicate that enrofloxacin-mediated NET formation requires functional tubulin and actin filaments, similar to previously shown data for chromatin release by neutrophils in response to LPS [15].

\section{Antimicrobial Activity of Enrofloxacin-Treated}

\section{Granulocytes against MRSA}

Finally, the overall effect of enrofloxacin on the antimicrobial acitivity of granulocytes against MRSA was tested by plating surviving bacteria after coincubation. Therefore, a well-characterized nuclease-deficient strain [14], which is susceptible to NET-mediated killing, was used besides its NET-resistant wild-type strain, which is able to degrade NETs. The combination of these two strains offers the ability to characterize NET-mediated antimicrobial effects. The data are given as percentages of surviving bacteria in the presence of granulocytes treated with enrofloxacin compared to surviving bacteria in the presence of granulocytes treated with $\mathrm{NaOH}(100 \%)$. As shown in fig. $2 \mathrm{f}$, enrofloxacin-treated granulocytes exhibited a slight but significantly enhanced antimicrobial ac- 


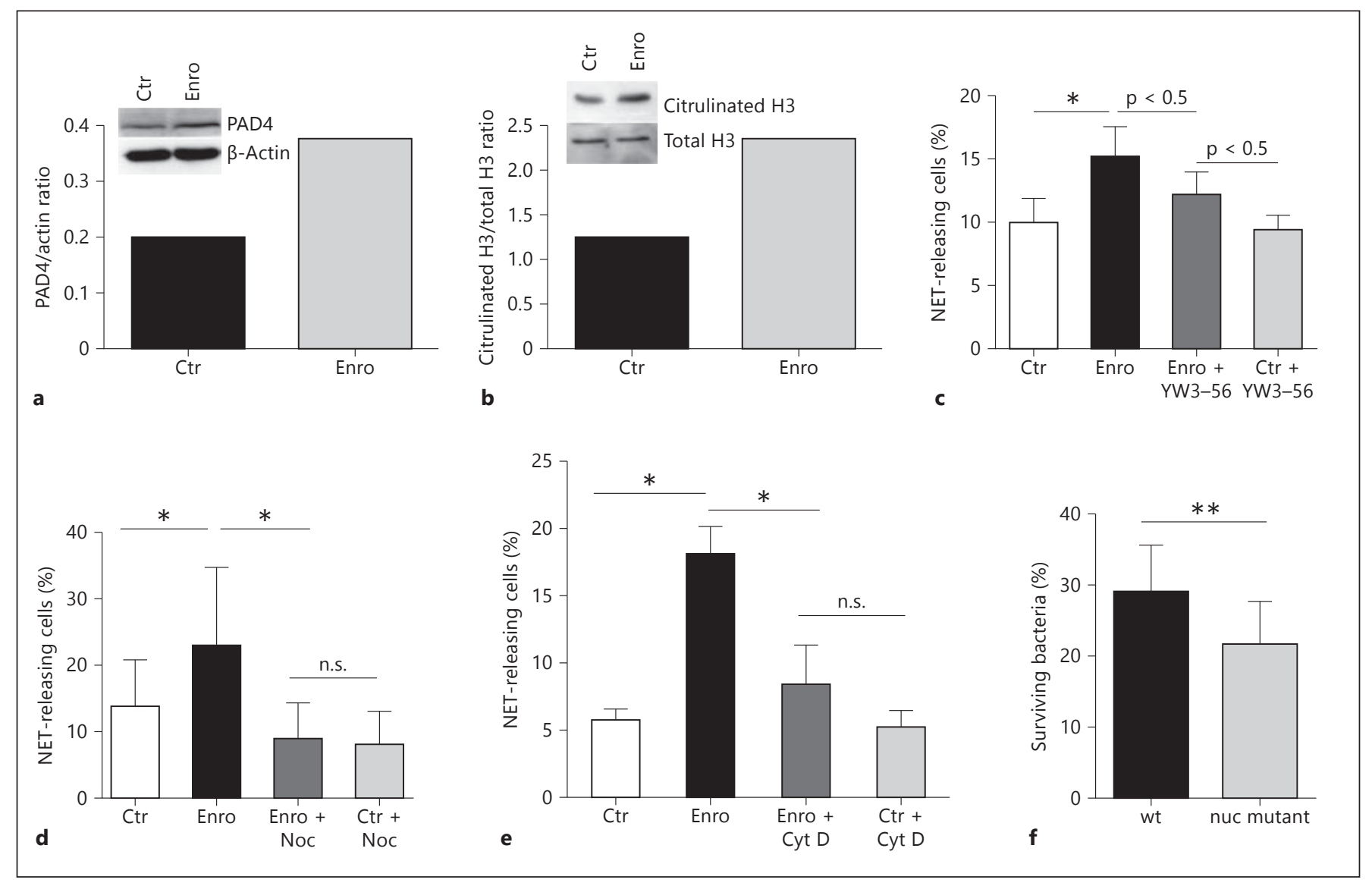

Fig. 2. Biochemical mechanisms associated with the enrofloxacininduced formation of NETs. Bovine granulocytes were treated with $10 \mu \mathrm{g} / \mathrm{ml}$ enrofloxacin for $2 \mathrm{~h}$. a Effect of enrofloxacin on PAD4 protein expression as analyzed by Western Blot. b Effect of enrofloxacin on histone $\mathrm{H} 3$ citrullination as analyzed by Western Blot. The results from pooled granulocytes derived from 3 individual animals are shown. c Effect of PAD4 inhibition with $8 \mu \mathrm{M}$ YW3-56 on enrofloxacin-mediated NET formation in bovine granulocytes. The results of 12 images from 2 independent experiments are shown. Effect of nocodazole (Noc) (d) and cytochalasin D (Cyt D) (e) on enrofloxacin-mediated NET formation in bovine granulo-

tivity against the NET-susceptible nuc mutant compared to the NET-resistant wild-type strain, assuming that NETs play a role in the given antimicrobial effect.

\section{Conclusions}

In summary, this is the first report to show that an antibiotic chemotherapy modulates the ROS-dependent formation of NETs as a novel innate immune function of granulocytes, facilitating the entrapment and subsequent cytes. The results of 3 independent experiments with 5 images each are shown. $\mathbf{f}$ Impact of enrofloxacin-mediated NET formation on antimicrobial activity against MRSA (4 independent experiments); the antimicrobial effect was measured by quantifying the surviving colony-forming units of the MRSA strain USA 300 LAC wild type (wt) and its respective NET-susceptible nuc mutant. Data are presented as percentages of surviving bacteria in the presence of granulocytes treated with enrofloxacin compared to surviving bacteria in the presence of granulocytes treated with $\mathrm{NaOH}(100 \%)$. All results were analyzed using a paired (d-f) or unpaired (c) onetailed t test. n.s. $=$ Not significant; ${ }^{*} \mathrm{p}<0.05$ and ${ }^{* *} \mathrm{p}<0.005$. 
vading pathogens and their released toxins, thereby diminishing the high inflammatory reactions during bacteriostatic antibiotic treatment.

Overall, the observed effects of enrofloxacin on bovine granulocyte functions might be of importance during treatment of infectious diseases in normal and immunocompromised animals. In general, the ability of an antibiotic chemotherapy to induce NET formation could substantially influence the management of an infection.

\section{Acknowledgements}

We wish to thank Friederike Reuner for excellent technical assistance and Marc Monestier for providing the anti-histone-DNA antibody used to visualize the NETs.

This work was supported by a grant from the Akademie für Tiergesundheit (AfT) to Natalja Jerjomiceva, a grant from the German Academic Exchange Service (DAAD) to Nathalie Zeitouni and Seri Hisham, and NCI/NIH grant R01 CA136856 to Yanming Wang.

\section{References}

1 Barlow J: Mastitis therapy and antimicrobial susceptibility: a multispecies review with a focus on antibiotic treatment of mastitis in dairy cattle. J Mammary Gland Biol Neoplasia 2011;16:383-407.

2 Boothe DM: Enrofloxacin revisited. Vet Med 1994;8:744-753.

$\checkmark 3$ Hoeben D, Dosogne H, Heyneman R, Burvenich C: Effect of antibiotics on the phagocytotic and respiratory burst activity of bovine granulocytes. Eur J Pharmacol 1997;332:289-297.

4 Ziv G, Gordin S, Bachar G, Bernstein S: Concentration and persistence of antibiotics in milk following intramammary infusion in cows. Refuah Vet 1973;30:85-100.

$>5$ Burvenich C, Paape MJ, Hill AW, Guidry AJ, Miller RH, Heyneman R, Kremer WDJ, Brand A: Role of the neutrophil leukocyte in the local and systemic reactions during experimentally induced $E$. coli mastitis in cows immediately after calving. Vet Q 1994;16:45-50.

6 von Köckritz-Blickwede M, Nizet V: Innate immunity turned inside-out: antimicrobial defence by phagocyte extracellular traps. J Mol Med 2009;87:775-783.

7 Brinkmann V, Reichard U, Goosmann C, Fauler B, Uhlemann Y, Weiss DS, Weinrauch Y, Zychlinsky A: Neutrophil extracellular traps kill bacteria. Science 2004;303:1532-1535.
8 Aulik NA, Hellenbrand KM, Klos H, Czuprynski CJ: Mannheimia haemolytica and its leukotoxin cause neutrophil extracellular trap formation by bovine neutrophils. Infect Immun 2010;78:4454-4466.

-9 Grinberg N, Elazar S, Rosenshine I, Shpigel NY: Beta-hydroxybutyrate abrogates formation of bovine neutrophil extracellular traps and bactericidal activity against mammary pathogenic Escherichia coli. Infect Immun 2008;76:2802-2807.

10 Behrendt JH, Ruiz A, Zahner H, Taubert A, Hermosilla C: Neutrophil extracellular trap formation as innate immune reactions against the apicomplexan parasite Eimeria bovis. Vet Immunol Immunopathol 2010;133:1-8.

11 Losman MJ, Fasy TM, Novick KE, Monestier M: Monoclonal autoantibodies to subnucleosomes from a MRL/Mp(-)+/+ mouse: oligoclonality of the antibody response and recognition of a determinant composed of histones H2A, H2B, and DNA. J Immunol 1992;148: 1561-1569.

12 Wang Y, Li P, Wang S, Hu J, Chen XA, Wu J, Fisher M, Oshaben K, Zhao N, Gu Y, Wang D, Chen G, Wang Y: Anticancer peptidylarginine deiminase (PAD) inhibitors regulate the autophagy flux and the mammalian target of rapamycin complex 1 activity. J Biol Chem 2012;287:25941-25953.
13 Wang Y, Wysocka J, Sayegh J, Lee YH, Perlin JR, Leonelli L, Sonbuchner LS, McDonald CH, Cook RG, Dou Y, Roeder RG, Clarke S, Stallcup MR, Allis CD, Coonrod SA: Human $\mathrm{PAD} 4$ regulates histone arginine methylation levels via demethylimination. Science 2004; 306:279-283.

14 Berends ETM, Horswill AR, Haste NM, Monestier M, Nizet V, von Köckritz-Blickwede M: Nuclease expression by Staphylococcus aureus facilitates escape from neutrophil extracellular traps. J Innate Immun 2010;2: 576-586.

15 Neeli I, Dwivedi N, Khan S, Radic M: Regulation of extracellular chromatin release from neutrophils. J Innate Immun 2009;1:194201.

16 Wang Y, Li M, Stadler S, Correll S, Li P, Wang D, Hayama R, Leonelli L, Han $H$, Grigoryev SA, Allis CD, Coonrod SA: Histone hypercitrullination mediates chromatin decondensation and neutrophil extracellular trap formation. J Cell Biol 2009; 184:205-213.

-17 Dosogne H, Meyer E, Sturk A, van Loon J, Massart-Leën AM, Burvenich C: Effect of enrofloxacin treatment on plasma endotoxin during bovine Escherichia coli mastitis. Inflamm Res 2002;51:201-205. 